\title{
MEDIA AUDIO VISUAL UNTUK MENINGKATKAN KEMAMPUAN MENYIMAK DONGÉNG
}

\author{
Mella Lisyanti Gustiar \\ SMAN 1 Manonjaya \\ email: mellalisyantigustiar@gmail.com
}

\begin{abstract}
Abstrak
Penelitian ini bertujuan untuk mengetahui bagaimana efektivitas media audio-visual dalam mendengarkan dongeng, yang diajarkan dengan menggunakan bantuan audio visual (media), serta hasil belajar siswa di kelas yang menggunakan metode konvensional. Subyek dalam penelitian ini adalah siswa Kelas X SMA Negeri 1 Manonjaya Tasikmalaya Tahun Akademik 20122013/, yang dibagi menjadi kelompok eksperimen dan kelompok kontrol. Setiap kelompok terdiri atas 30 orang, yang pilih secara acak. Pengolahan data dalam penelitian ini dilakukan melalui pengujian sifat data, uji gain, dan hipotesis. Hasil penelitian menunjukkan bahwa terdapat perbedaan signifikan hasil dari Kelas X SMA Negeri 1 Manonjaya Tasikmalaya antara siswa yang menggunakan media audio visual dibandingkan dengan siswa yang menggunakan metode konvensional. Dimana hasil belajar siswa yang diajarkan dengan menggunakan audio visual media $(17,06)$ lebih tinggi daripada hasil belajar siswa yang diajarkan dengan menggunakan metode konvensional $(10,00)$. Temuan dari penelitian adalah guru perlu menggunakan media berbasis teknologi dalam mengajar, sebagai contoh bisa menggunakan bantuan audio visual, sehingga hasil belajar bisa dicapai secara optimal, terutama untuk mendengarkan pelajaran menyimak dongeng.
\end{abstract}

Kata kunci: media audio-visual, metode konvensional

\section{AUDIO-VISUAL AIDS IN ENHANCING THE ABILITY TO LISTEN TO FOLTALES}

\begin{abstract}
This reseach aims to identify the effectiveness of audio-visual media in teaching folktales, comparing instruction with audio-visual aids to that with a conventional method. The research subjects were grade X students of SMA Negeri 1 Manonjaya Tasikmalaya 2012/2013 academic year, divided into an experiment group and a control group. Each group consisted of 30 people, randomly chosen. The data were investigated by testing their nature, the test gain, and hypotheses. Results indicate that there was a significant difference between instruction with audio visual aid compared to instruction with a conventional method. The achievement results of students in an audio visual class were $(17,06)$ higher than those in a conventional method class $(10,00)$. The findings suggest that teachers need to apply media-based teaching, e.g.using audio-visual aids to achieve an optimal learning, especially in teaching folktales.
\end{abstract}

Key words: audio-visual aids, conventional method 


\section{PENDAHULUAN}

Perkembangan teknologi tentunya memberikan banyak pengaruh pada dunia pendidikan. Salahsatu perkembangan dalam dunia pendidikan adalah terciptanya media pembelajaran yang lebih variatif dan menarik. Media pembelajaran yang menarik bisa menciptakan suasana belajar siswa yang menyenangkan.

Media merupakan wahana penyalur informasi belajar atau penyalur pesan. Gerlach dan Elly dalam Arsyad (2007:3) mengatakan bahwa media apabila dipahami secara garis besar adalah manusia, materi atau kajadian yang membangun kondisi yang membuat siswa mampu memperoleh pengetahuan, keterampilan, dan sikap. Banyak media yang bisa digunakan dalam pembelajaran sesuai dengan karakteristik bahan ajar.

Salah satu media pembelajaran yang bisa dijadikan alternatif adalah media audio visual. Media audio visual bisa menciptakan suasana menyenangkan bagi siswa. Media ini menggabungkan unsur visualisasi dan unsur audio dalam satu pemakaian sacara bersamaan dalam satu waktu.

Heinz Kock dalam Wuryani (2008: 3) yang menyebutkan bahawa media audio visual merupakan media yang mempunyai unsur suara dan unsur gambar. Media audio visual berbasis teknologi digunakan dalam mengoptimalkan proses pembelajaran dikarenakan beberapa aspek antara lain: (1) mudah dikemas dalam proses pembelajaran; (2) lebih menarik untuk pembelajaran; dan (3) dapat di-edit (diperbaiki) setiap saat. Dengan pemanfaatan teknologi komputer diharapkan bahwa media audio visual dapat digunakan untuk menyampaikan materi bahan ajar sehingga menarik di kalangan siswa.

Mata pelajaran menyimak dongeng adalah pelajaran yang membutuhkan pemahaman mendalam dan komprehensif. Terlebih menyimak merupakan kegiatan yang paling banyak dilakukan oleh siswa. Dalam kegiatan belajar siswa harus bisa menyimak apa yang disampaikan guru secara baik dan benar agar tujuan pembelajaran bisa tercapai dengan baik. Oleh sebab itu, alangkah tidak etis apabila ada tafsiran bahwa di antara empat keterampilan berbahasa, menyimak yang paling mudah. Seperti yang dikemukakan oleh Hermawan (2012: 30) "Menyimak merupakan sebuah keterampilan yang kompleks yang memerlukan ketajaman perhatian, konsentrasi, sikap mental yang aktif dan kecerdasan dalam mengasimilasi serta menerapkan setiap gagasan".

Artinya, menyimak adalah proses yang selektif atau memilih dari sekian banyaknya rangsangan di sekitar kita, milih yang mana yang paling dibutuhkan. Proses ini menerima beberapa rangsangan terhadap pusat persepsi menyimak. Ketika menyimak dibutuhkan konsentrasi untuk memusatkan perhatian terhadap rangsangan yang sifatnya refleks dan mengakibatkan perubahan. Seperti suara-suara atau lambang-lambang lisan atau gagasangagasan yang disimak.

Dongeng adalah cerita rekaan yang ukurannya pendek. Berdasarkan isinya, dongeng dibagi menjadi beberapa bagian, di antaranya: (1) dongéng sasatoan; (2) dongéng sasakala; (3) dongéng babad; (4) dongéng jelema biasa; (5) dongéng para nabil wali; (6) dongéng pieunteungeun; (7) dongéng pamuk (Tamsyah, 1997: 121).

Adapun usur-unsurnya ada lima, yaitu: (1) tema; (2) Palaku; (3) galur; (4) latar; dan (5) amanat. Tema, adalah inti pikiran atau pusat imagi pengarang atau inti dari dongeng. Palaku adalah pemeran atau tokoh dalam cerita bisa manusia bisa hewan bisa juga tumbuhan, banyak sedikitnya tokoh dalam cerita tergantung pada ceritanya itu sendiri. Latar ada dua yaitu latar tempat dan latar waktu. Galur atau plot adalah susunan waktu kejadian dalam cerita. Amanat adalah pesan yang ingin disampaikan pengarang.

Dalam kenyataannya, pelajaran menyimak kurang diperhatikan oleh siswa atau bisa jadi dianggap sebagai perkara yang sepele. Berdasarkan hasil pengamatan, terdapat beberapa kesulitan siswa dalam pembelajaran menyimak, di antaranya: (1) siswa kurang 
paham tentang pentingnya keterampilan menyimak hususnya dalam pelajaran menyimak dongeng; (2) penyampaian materi yang tidak menarik menyebabkan siswa menjadi kurang antusias; (3) penggunaan media pembelajaran di SMAN 1 Manonjaya masih minim; dan (4) tehnik pembelajaran dalam menyimak yang kurang variatif. Hal-hal itu yang menjadi sebab rendahnya kemampuan siswa kelas X SMAN 1 Manonjaya Tasikmalaya dalam pelajaran menyimak dongeng.

Untuk menanggulangi masalah tersebut perlu diadakan pembelajaran berbasis media. Hal ini dilakukan agar kecakapan siswa dalam pelajaran menyimak dongeng meningkat, serta tujuan pembelajaran bisa tercapai dengan baik. Media yang pembelajaran yang sosok untuk meningkatkan kemampuan siswa dalam menyimak adalah media audio visual. Sebagaimana yang diungkapkan oleh penelitian sebelumnya, di antaranya: (1) melalui media audio visual, nilai rata-rata pengajaran menyimak pupuh sekar ageung mengalami peningkatandari siklus I yang besarnya 83 , 95 meningkat menjadi 91,05 di siklus II (Barliani, 2013: 57); (2) kemampuan menyimak kelas eksperimen yang menggunaken media audio visual mengalami peningkatan yang signifikan yaitu sebesar 9,6 dari skala nilai 100 dibandingkan dengan kelas kontrol yang tidak menggunakan media audio visual (Suparno, 2012: 134).

Dikarenakan hasil akhir yang meningkat serta belum ada penelitian yang meneliti mengenai pengaruh media audio visual terhadap pengajaran menyinak dongeng di kelas $\mathrm{X}$ SMAN 1 Manonjaya Tasikmalaya, maka penulis tertarik untuk menggunakan media di atas dalam pelajaran menyimak dongeng.

Berdasarkan latar belakang tersebut maka dapat dirumuskan masalah "bagaimana efektivitas pemanfaatan media audio visual sebagai alternatif optimalisasi dalam pelajaran menyimak dongeng di kelas X SMAN 1 Manonjaya Tasikmalaya. Selanjutnya tujuan dari penelitian ini adalah untuk mengetahui bagaimana keefektifan hasil belajar siswa kelas X SMAN 1 Manonjaya Tasikmalaya pada mata pelajaran menyimak dongeng dengan menggunakan media audio visual. Di samping itu, penelitian ini diharapkan: (1) dapat mengembangkan kreativitas siswa dan guru dalam penerapan teknologi informasi dan komunikasi sebagai media pembelajaran; (2) dapat menambah wawasan insan pendidikan mengenai efektivitas pemanfaatan media audio visual dalam pembelajaran; dan (3) memberikan kemudahan proses pembelajaran dan menambah referensi bagi guru dalam proses pembelajaran.

\section{METODE}

Penelitian ini dilaksanakan di SMAN 1 Manonjaya Tasikmalaya, tepatnya di jalan Patrol Kulon Manonjaya-Tasikmalaya 46197. Penelitian ini. berpusat pada kemampuan siswa dalam menyimak dongeng menggunakan media audio visual.

Subjek dalam penelitian ini adalah seluruh siswa kelas X SMAN 1 Manonjaya Tasikmalaya tahun pelajaran 2012/2013. Subjek penelitian dipilih secara acak untuk menentukan mana kelas kontrol dan mana kelas eksperimen. Kelas X-3 sebagai kelas kontrol, dengan jumlah siswa 30 orang, 12 orang laki-laki, 18 orang perempuan. Sedangkan sebagai kelas eksperimen yaitu kelas X-4 yang jumlahnya sama 30 orang, 13 laki-laki dan 17 sisanya perempuan.

Metode yang digunakan dalam penelitian ini adalah metode kuasi eksperimen. Desain penelitian yang digunakan yaitu PretestPosttest, Non Equivalent Control Group Design (Syamsudin dan Vismaia, 2009: 159).

\section{HASIL DAN PEMBAHASAN}

Penelitian dilakukan pada tanggal 06, 13, 20, 27 Mei 2013 dengan waktu kurang lebih dua jam pelajaran (2x45 menit) yaitu dari pukul 08.15 sampai 09.45 WIB. Dimulai oleh guru membuka pembalajaran, apersepsi dan motivasi. Pertemuan pertama melaksanakan prates untuk mengetahui kemampuan awal siswa dalam menyimak dongeng sebelum 
perlakuan. Pertemuan kedua dan ketiga guru memberikan treatmen berupa dongeng-dongeng menggunakan bantuan media audio visual. Pertemuan keempat guru melaksanakan postes dengan tujuan untuk mengetahui kemampuan akhir siswa.

Untuk mengetahui berapa tingkat signifikansi media audio visual dalam pelajaran menyimak dongeng dapat di lihat di tabel 1 .

Tabel 1.

\section{Nilai Prates \& Postes Kelas Eksperimen} dan Kelas Kontrol

\begin{tabular}{|c|c|c|c|c|c|c|c|c|}
\hline \multirow[t]{2}{*}{ No. } & \multicolumn{2}{|c|}{$\begin{array}{c}\text { Kelas } \\
\text { Éksperimen }\end{array}$} & \multirow[t]{2}{*}{ (x) } & \multirow[t]{2}{*}{$\left(x^{2}\right)$} & \multicolumn{2}{|c|}{ Kelas Kontrol } & \multirow[t]{2}{*}{ (y) } & \multirow[t]{2}{*}{$\left(\mathrm{y}^{2}\right)$} \\
\hline & Prates & Postes & & & Prates & Postes & & \\
\hline (1) & (2) & (3) & (4) & (5) & (6) & (7) & (8) & (9) \\
\hline 1 & 76 & 88 & 12 & 144 & 76 & 88 & 12 & 144 \\
\hline 2 & 76 & 84 & 8 & 64 & 80 & 96 & 16 & 256 \\
\hline 3 & 80 & 92 & 12 & 144 & 64 & 76 & 12 & 144 \\
\hline 4 & 76 & 92 & 16 & 256 & 72 & 76 & 4 & 16 \\
\hline 5 & 72 & 96 & 24 & 576 & 68 & 84 & 16 & 256 \\
\hline 6 & 60 & 88 & 28 & 784 & 72 & 76 & 4 & 16 \\
\hline 7 & 80 & 96 & 16 & 256 & 76 & 84 & 8 & 64 \\
\hline 8 & 72 & 92 & 20 & 400 & 80 & 88 & 8 & 64 \\
\hline 9 & 68 & 76 & 8 & 64 & 60 & 84 & 24 & 576 \\
\hline 10 & 84 & 96 & 12 & 144 & 72 & 76 & 4 & 16 \\
\hline 11 & 64 & 80 & 16 & 256 & 76 & 92 & 16 & 256 \\
\hline 12 & 56 & 88 & 32 & 1024 & 84 & 80 & -4 & 16 \\
\hline 13 & 56 & 76 & 20 & 400 & 76 & 92 & 16 & 256 \\
\hline 14 & 68 & 92 & 24 & 576 & 68 & 76 & 8 & 64 \\
\hline 15 & 72 & 84 & 12 & 144 & 76 & 92 & 16 & 256 \\
\hline 16 & 76 & 96 & 20 & 400 & 76 & 76 & 0 & 0 \\
\hline 17 & 84 & 96 & 12 & 144 & 68 & 80 & 12 & 144 \\
\hline 18 & 60 & 72 & 12 & 144 & 68 & 80 & 12 & 144 \\
\hline 19 & 72 & 84 & 12 & 144 & 80 & 96 & 16 & 256 \\
\hline 20 & 76 & 92 & 16 & 256 & 80 & 92 & 12 & 144 \\
\hline 21 & 76 & 92 & 16 & 256 & 72 & 76 & 4 & 16 \\
\hline 22 & 76 & 96 & 20 & 400 & 80 & 80 & 0 & 0 \\
\hline 23 & 76 & 88 & 12 & 144 & 68 & 72 & 4 & 16 \\
\hline 24 & 76 & 92 & 16 & 256 & 60 & 80 & 20 & 400 \\
\hline 25 & 64 & 80 & 16 & 256 & 80 & 80 & 0 & 0 \\
\hline 26 & 72 & 96 & 24 & 576 & 76 & 80 & 4 & 16 \\
\hline 27 & 76 & 88 & 12 & 144 & 76 & 88 & 12 & 144 \\
\hline 28 & 64 & 88 & 24 & 576 & 84 & 96 & 12 & 144 \\
\hline 29 & 72 & 92 & 20 & 400 & 60 & 80 & 20 & 400 \\
\hline 30 & 72 & 92 & 20 & 400 & 60 & 72 & 12 & 144 \\
\hline$\Sigma$ & 2152 & 2664 & 512 & 9728 & 2188 & 2488 & 300 & 4368 \\
\hline $\begin{array}{l}\text { Rata- } \\
\text { rata }\end{array}$ & 71,73 & 88,8 & 17,06 & 324,27 & 72,9 & 82,9 & 10,00 & 145,60 \\
\hline
\end{tabular}

Dari tabel di atas dapat dilihat bahwa skor tertinggi prates di kelas eksperimen yaitu 84 , sedangkan skor terendah yaitu 56 , seumpama tingkat kemampuan siswa dalam menyimak ditentukan oleh KKM (Kriteria Ketuntasan Minimal) 80, jadi siswa yang sudah mampu menyimak dongeng dengan baik dan benar ketika prates hanya 4 orang dari 30 orang. Sehingga apabila dipersentasikan, siswa yang sudah mampu menyimak dongeng adalah $13 \%$ sedangkan sisanya sebesar $87 \%$ dianggap belum mampu menyimak dongeng dengan baik dan benar. Ketika postes siswa yang dianggap sudah mampu dalam pelajaran menyimak dongeng ada 27 siswa atau sekitar $90 \%$. Hal ini menunjukan bahwa kemampuan menyimak dongeng di kelas X-4 selaku kelas eksperimen mengalami kemajuan setelah menggunakan media pelajaran berbasis audio visual.

Sedangkan di kelas kontrol, skor tertinggi yaitu 84 sedangkan skor terendah adalah 60, seumpama tingkat kemampuan siswa dalam pelajaran menyimak dongeng dotentukan oleh KKM (Kritéria Ketuntasan Minimal) 80, jadi siswa yang dianggap mampu menyimak dongeng dengan baik dan benar ketika prates adalah 8 orang dari 30 orang. Jadi apabila dipresentasikan, siswa yang sudah mampu menyimak dongeng sebesar $27 \%$ sedangkan sisanya sebesar $73 \%$ dianggap belum mampu dalam pelajaran menyimak dongeng yaitu 21 orang atau sekitar $70 \%$.

Rata-rata beda hasil prates dan postes dalam pelajaran menyimak dongeng di kelas eksperimen sebesar 17,06 sedangkan di kelas kontrol sebesar 10,00. Untuk mengetahui efektif tidaknya media audio visual dalam pelajaran menyimak dongeng siswa kelas X SMAN 1 Manonjaya Tasikmalaya maka perlu diadakan uji hipotesis.

Dalam taraf kepercayaan 99\% dan dengan derajat kabébasan 29, diketahui nilai $t_{\text {tabél }}$ yang basarnya 2,45. Dari tabel di atas terlihat bahwa $\mathrm{t}$ itung $>\mathrm{t}$ tabél baik kelas eksperimen maupun kelas kontrol. Kelas eksperimen hasil $\mathrm{t}_{\text {itung }}$ nya 16,09, sedangkan kelas kontrol 8,00. Artinya, Hi diterima dan Ho ditolak. Ini menunjukan bahwa pembelajaran dongeng menggunakan media audio visual lebih efektif daripada pembelajaran dengan menggunakan media yang konvensional. 


\section{SIMPULAN}

Berdasarkan analisis data dari pengaruh media audio visual terhadap pelajaran menyimak dongeng siwa kelas X SMAN 1 Manonjaya Tasikmalaya dapat disimpulkan sebagai berikut:

1) Kemampuan siswa kelas eksperimen SMAN 1 Manonjaya Tasikmalaya ketika prates hanya 4 orang atau sekitar $13 \%$ yang dianggap sudah mampu menyimak dongeng, sisanya 26 orang atau $87 \%$ dianggap belum mampu meyimak dongeng dengan baik dan benar. Setelah postes siswa yang dianggap mampu menyimak dongeng dengan baik dan benar meningkat menjadi 27 orang atau kurang lebih $90 \%$, sisanya 3 orang atau $10 \%$ dianggap belum mampu dalam menyimak dongeng dengan baik dan benar.

2) Kemampuan siswa kelas kontrol SMAN 1 Manonjaya Tasikmalaya ketika prates hanya 8 orang atau sekitar $26 \%$ yang dianggap sudah mampu menyimak dongeng, sisanya 22 orang atau $74 \%$ dianggap belum mampu meyimak dongeng dengan baik dan benar. Setelah postes siswa yang dianggap mampu menyimak dongeng dengan baik dan benar meningkat menjadi 21 orang atau kurang lebih $70 \%$, sisanya 9 orang atau $30 \%$ dianggap belum mampu dalam menyimak dongeng dengan baik dan benar.

3) Kemampuan menyimak dongeng di kelas eksperimen lebih besar dibandingkan dengan kelas kontrol, terlihat dari beda rata-rata hasil prates dan postes yang besarnya 17,06 di kelas eksperimen dan 10,00 di kelas kontrol.

4) Pelajaran menyimak dongeng di kelas eksperimen yang menggunakan media audio visual lebih efektif dari pembelajaran yang menggunakan media konvensional di kelas kontrol. Terlihat bahwa $\mathrm{t}_{\text {itung (eksperimen) }} 16,09$ $>\mathrm{t}_{\text {tabél }} 2,45$ sedangkan $\mathrm{t}_{\text {itung (kontrol) }} 8,00>\mathrm{t}_{\text {tabél }}$
2,45 . Artinya, hipotésis dalam penelitian ini diterima, bahwa media audio visual efektif untuk pelajaran menyimak dongeng siswa kelas X SMAN 1 Manonjaya Tasikmalaya tahun pelajaran 2012/2013.

\section{PUSTAKA RUJUKAN}

Arsyad, Azhar. (2007). Media Pembelajaran. Jakarta: PT. Raja Grafindo Persada.

Barliani, Karina. (2013). "Média Audio Visual pikeun Ngaronjatkeun Kamampuh Ngaregepkeun Tembang Pupuh Sekar Ageung". Skripsi FPBS UPI Bandung: tidak diterbitkan.

Hermawan, Herry. (2012). Menyimak: Keterampilan Berkomunikasi yang Terabaikan. Yogyakarta: Graha Ilmu.

Suparno. (2012). Peningkatan Keterampilan Menyimak dan Menulis melalui Sistem Pembelajaran Modul dengan Media Audio Visual dalam Pembelajaran Bahasa Indonesia. Tesis PASCASARJANA UPI Bandung: tidak diterbitkan.

Tamsyah, Budi Rahayu. (1997). Pangajaran Sastra Sunda. Bandung: CV. Pustaka Setia. Wuryani, Tri. (2008). Media Pembelajaran. [on line]. Tersedia: http://triwuryani. files.wordpress.com $/ 2008 / 01 /$ mediapembelajaran.ppt. [20 April 2013].

\section{UCAPAN TERIMA KASIH}

Penulis mengucapkan terima kasih dan penghargaan kepada Prof. Dr. H. Rahman, M.Pd. dan Dr. H. Dingding Haerudin, M.Pd. sebagai pembimbing. Selain itu, juga kepada Ketua Prodi Pendidikan Bahasa dan Budaya Sunda SPs UPI, Ketua Prodi Jurusan Pendidikan Bahasa Daerah FPBS UPI, dan Kepala Sekolah SMA Rimba Madya Bogor. Terima kasih pula penulis sampaikan kepada redaksi Jurnal Lokabasa atas dimuatnya tulisan ini. 